https://doi.org/10.46813/2021-131-092

\title{
EXPERIMENTAL AND NUMERICAL STUDIES OF PRESSURE AND GAP LENGTH EFFECTS ON ENERGY DEPOSITION IN SPARK DISCHARGE
}

\author{
K.V. Korytchenko ${ }^{1}$, I.S. Varshamova ${ }^{1}$, D.V. Meshkov ${ }^{1}$, D.P. Dubinin ${ }^{2}$, \\ R.I. Kovalenko ${ }^{2}$, S.Yu. Nazarenko ${ }^{2}$ \\ ${ }^{1}$ National Technical University "KhPI", Kharkiv, Ukraine; \\ ${ }^{2}$ National University of Civil Defence of Ukraine, Kharkiv, Ukraine \\ E-mail: omsroot@kpi.kharkov.ua; korytchenko_kv@ukr.net
}

\begin{abstract}
A study of the influence of the discharge gap length and the initial gas pressure on the energy deposition into the discharge channel was done. The study was conducted at the same total discharge energy. It is experimentally shown that the connection of the voltage probe to the discharge circuit significantly affects the discharge current. The determination of the energy deposited into the spark channel is based on the results of numerical simulation of the spark channel development. Experimentally measured discharge currents at different pressures and the gap length were used as initial data for the calculation. Based on the obtained results, it is determined which of the factors (the initial pressure or the gap length) has the strongest influence on the energy input into the spark channel.
\end{abstract}

PACS: $52.80 . \mathrm{Mg}$

\section{INTRODUCTION}

Spark discharge is used in many devices, where the initial pressure and length of the spark gap varies widely [1-3]. For applied problems, there is a need to determine the effect of pressure and the discharge gap length on the energy input into the spark. But in this case there is a problem in the separation of these effects on the energy deposition into the spark discharge. This is because a change in the initial gas pressure or the spark gap length leads to a change in the breakdown voltage of the gap. Therefore, under constant other parameters of the discharge circuit, under these conditions there is a change in the total discharge energy due to the increase in the charging voltage of the capacitor to have the spark breakdown. As a result, it makes it difficult to detect the effect of the initial gas pressure or the spark gap length on the energy deposition into the spark channel under conditions of change in the total discharge energy [1]

To prevent a change in the total discharge energy under conditions of change in gas pressure or the length of the gap, it is possible to use a discharge circuit with series-connected three-electrode triggered spark gaps [4]. But the presence of such triggered gaps also affects the energy input into the spark channel, because it adds a variable resistance in the discharge circuit. Therefore, there is a need to create a special technique for measuring such effects.

An experimental study of the effect of the initial gas pressure and the discharge gap length on the energy input into the spark discharge was carried out in work [1$3,5]$, but the separation of these effects from the influence of other factors was not performed. The use of numerical models of the expansion of the spark channel allows studying the spark discharge at constant total discharge energy by invariable parameters of the electric circuit $[6,7]$. This approach is used to study the effect of initial pressure on the spark evolution [8, 9]. The influence of the gap length was studied in work [10]. At the same time, there are no experimental works in which the influence of the initial gas pressure and the gap length was studied at invariable total discharge energy. Therefore, in this work, a study was carried out at invariable discharge energy.

There are problems to experimentally measure the energy input into the spark channel. In particular, the calculation-experimental method based on measurements of discharge current and voltage across the discharge gap is widespread $[12,13]$. But in work [14] it is shown that a connection of the voltage probe to the measured spark gap leads to the influence on the discharge process that significantly changes the discharge current and voltage across the discharge gap. The study of this effect was performed for a spark discharge with the total energy equals to several micro Joules. Therefore, there is a need to verify this effect when the total discharge energy is increased. Therefore, we investigated such an impact when the total energy exceeds a hundred of milli Joules.

Thus, the aim of this work is a calculationexperimental study of the influence of the initial pressure and the length of the spark gap on the energy input into the discharge channel by invariable total discharge energy.

\section{TECHNIQUE AND METHODS OF MEASUREMENTS}

The capacitor discharge through the spark gap was investigated. A condition when a spark breakdown happens by an invariable voltage supplied to the spark gap is provided if the initial gap pressure and the gap length are variable. For this purpose, the known dependence of the breakdown voltage $u_{b r}$ is used

ISSN 1562-6016. BAHT. 2021. №1(131) 


$$
u_{b r} \sim p \cdot d,
$$

where $p$ is the initial gas pressure; $d$ is the spark gap length.

Thus, the change in the length of the discharge gap was compensated by the change in the initial gas pressure to achieve an invariable breakdown voltage. As a result, a spark discharge was ignited by constant total discharge energy and invariable parameters of the electric circuit.

The setup was assembled according to the scheme (Fig. 1). To change the initial gas pressure, the discharge gap 1 was placed in the high pressure chamber 2 . The pressure chamber was connected to a high pressure gas tank 3. Compressed air was supplied through a valve 4 . The initial gas pressure in the chamber was measured by a manometer 5. Gas outflow from the chamber was carried out through the valve 6 . The voltage was measured by a voltage probe 7 (resistive capacitive voltage divider). The measurement of the discharge current was carried out by a current sensor 8 using the Hall effect. The capacitor $C$ was charged from the step-up transformer $T_{2}$, the primary circuit of which was connected to the laboratory autotransformer $T_{1}$, and the secondary winding of this transformer was connected to the capacitor $C$ through the rectifier diode $V D$ and the current limiting resistor $R_{c h}$. High-frequency litz wire was used to connect the capacitor with the spark gap. An additional intermediate connection points for the voltage probe was made between the gap and the capacitor.

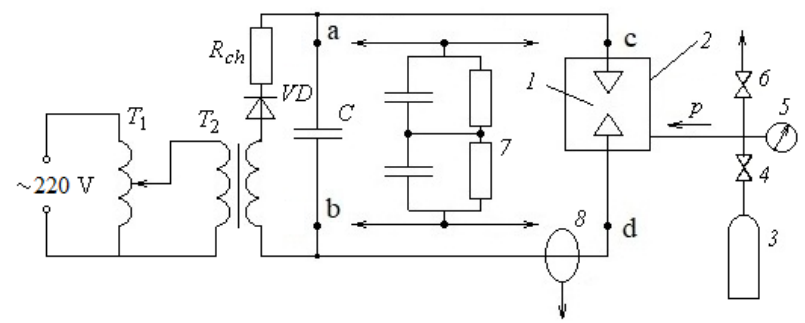

Fig. 1. Scheme of the setup

A capacitor type K15-10 with a capacity of $4700 \mathrm{pF}$ $\pm 30 \%$ was used as a discharge capacitor. Steel electrodes are used. PINTEK HVP-15HF voltage sensor was applied as a voltage probe. A Honneywell CSNM191 sensor was used to measure the current. The electrical connection between the capacitor and the spark gap was made by a litz wire with a LESHO type $1075 \times 0.071 \mathrm{~mm}$ to reduce the skin effect on the resistance of the electrical circuit. The total length of the litz wire was $1.5 \mathrm{~m}$. Measured signals from current and voltage sensors were recorded by Rigol DS1102E oscilloscope. The change in the length of the gap occurred in the range of $1 \ldots 2 \mathrm{~mm}$. The absolute gas pressure in the chamber was adjusted in the range from 0.1 to $0.2 \mathrm{MPa}$. The length of the discharge gap was measured by a caliper with a measurement accuracy of $\pm 0.1 \mathrm{~mm}$. Gas pressure was measured by a manometer DM05063 with 2.5 class accuracy. The resistance of the charging resistor was $43 \mathrm{k} \Omega$. Taking into account the high variance of the actual capacitance of the discharge capacitor, the measurement of its actual capacitance was performed by a digital impedance meter E7-22.
The view of the discharge circuit with measuring equipments is presented in Fig. 2.

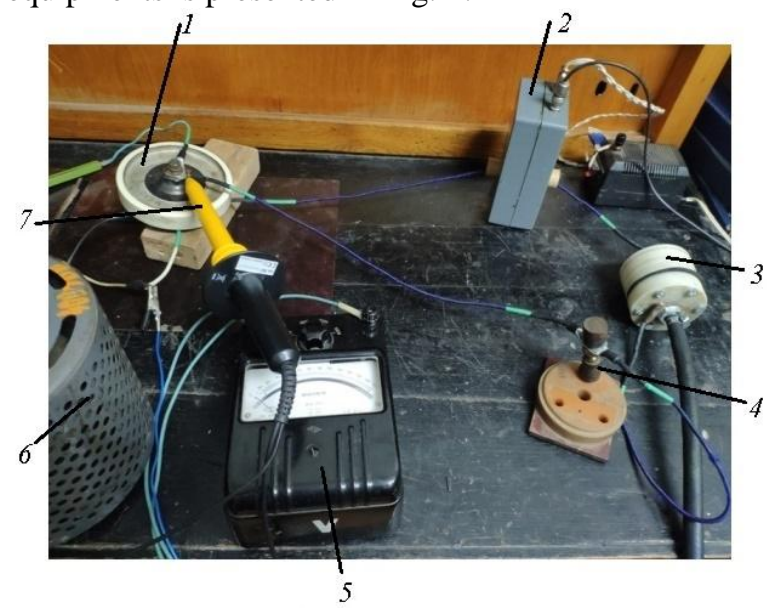

Fig. 2. Discharge circuit with measuring equipments: 1 -capacitor; 2 -current sensor; 3 -discharge gap placed in the high pressure chamber; 4 -additional intermediate connection points; 5 -voltmeter; 6 - laboratory autotransformer; $7-H V$ probe

The follow sequence of measurements was applied. The measurement was carried out at an invariable breakdown voltage of the discharge gap, but different initial gas pressure and gap length. To achieve these conditions, the required length of the discharge gap was set. Next, the chamber where the discharge gap was placed was filled with compressed gas. The gas pressure was set in such a way that in the case of supplying a required voltage to the discharge gap, the breakdown by this voltage did not occur. After that, the required voltage was supplied to the discharge gap. Next, the gas supply valve was closed, and the outlet valve was opened to exhaust the gas from the chamber. During the slow gas outflow, the manometer was monitored. After reducing the gas pressure, the breakdown of the discharge gap happened at a required voltage. When the breakdown happened, the pressure value was measured. Also, signals from current and pressure sensors were oscillated simultaneously in standby mode. Synchronization of input signals was carried out by the falling signal from the voltage sensor.

The measurement of the discharge current was performed at different connection points of the voltage probe. At first case, the probe was connected directly to the capacitor. At the second case, it was connected at the intermediate point (Fig. 2). At the third case, it was connected to the discharge electrodes.

\section{MEASUREMENT RESULTS}

According to the measurement of the capacitance of the discharge circuit, it was found that the capacitance without a connected voltage probe was equal to $(4.92 \pm$ $0.04) \mathrm{nF}$. In the case of connecting a voltage probe to an electrical circuit, the capacitance of the circuit increased to $(4.93 \pm 0.04) \mathrm{nF}$.

The results of the study revealed the influence of the connection point of the voltage probe on the discharge current. In particular, the results of measuring the current in the discharge circuit and the voltage at different 
connection points are shown in Figs. 3-5. In the presented oscillograms, the voltage sensitivity is $2.5 \mathrm{kV} /$ division, and the current sensitivity is $180 \mathrm{~A} /$ division.

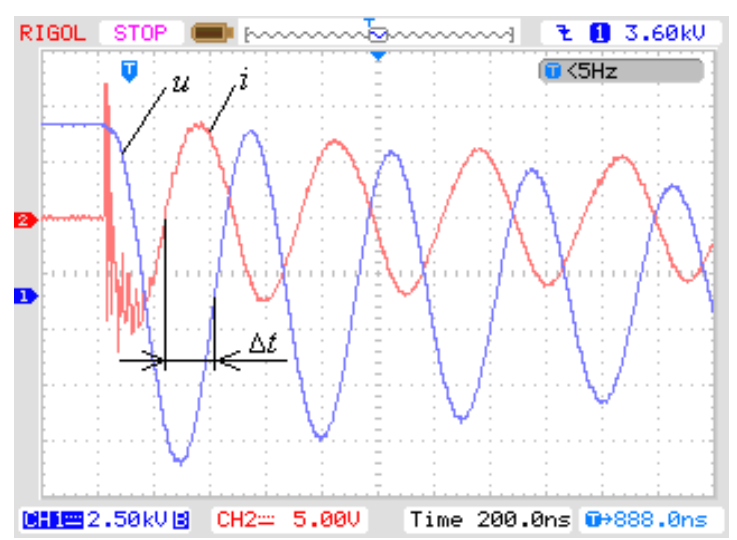

Fig. 3. Oscillograms of current $\boldsymbol{i}$ in the discharge circuit and voltage $\boldsymbol{u}$ when the voltage probe connected to the capacitor

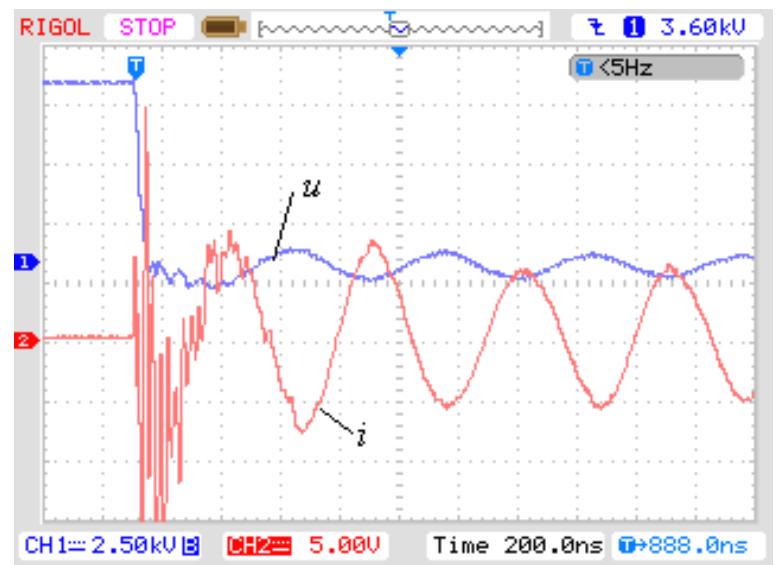

Fig. 4. Oscillograms of current $\boldsymbol{i}$ in the discharge circuit and voltage $\boldsymbol{u}$ when the voltage probe connected to the spark gap

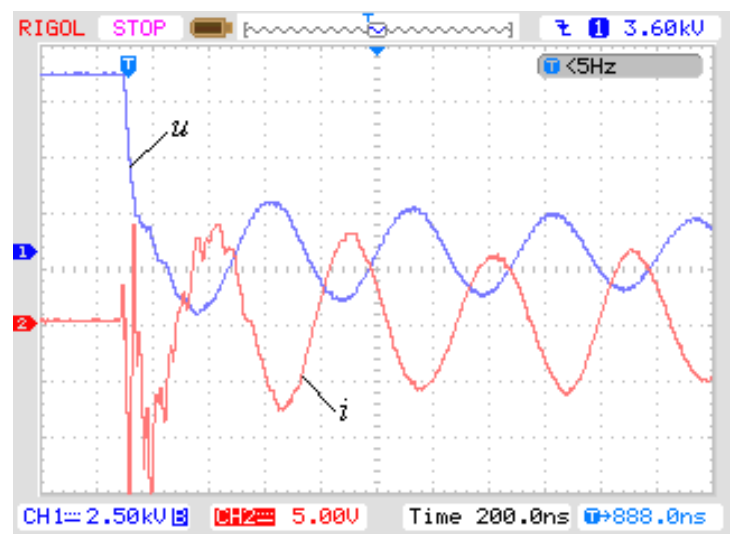

Fig. 5. Oscillograms of current $\boldsymbol{i}$ in the discharge circuit and voltage $\boldsymbol{u}$ when the voltage probe connected to the intermediate connection points

According to the measurement results, we observe the current which is characteristic of the oscillating damping discharge of the capacitor.

According to the measurement results (see Fig. 3), we have that the period of oscillations during the first period of the discharge is equal to about
$T \approx(490 \pm 10)$ ns. Hence, the inductance $L_{S C}$ of the $L C$-circuit can be determined from the following equation

$$
\omega=\frac{2 \pi}{T}=\sqrt{\frac{1}{L_{S C} C}},
$$

where $\omega$ is an angular frequency.

Taking into ccount that the capacitance equals to $C=4.92 \mathrm{nF}$ and period is $T=490 \mathrm{~ns}$, we have the circuit inductance of $L_{S C} \approx 1.24 \mu \mathrm{H}$.

We observe in Fig. 3 that the phase shift between voltage and current is not equal to $90^{\circ}$, which reflects the presence the self inductance of the capacitor and the resistance additionally to the capacitance in the measured circuit branch. If $\varphi=90^{\circ}$, then the maximum value of current in a series LC-circuit would correspond to zero value of voltage across the capacitor. And this is not observed on the measured oscillogram (see Fig. 3).

We observe that the connection of the voltage probe to different points led to a change in the discharge current (see Figs. 3-5). Higher harmonics are superimposed on the main harmonic of the current reflecting the oscillating discharge. In this case, the smallest amplitude of the higher harmonics occurs when the voltage probe is connected directly to the discharge capacitor.

This effect of connecting a voltage probe on the discharge current is explained by the fact that in the conducted research the discharge circuit cannot be represented by lumped circuit elements, similar to $R L C$ circuit. It is known that the discharge gap have a capacitance, and in the process of the spark discharge development there is a change in the resistance of the spark discharge and the inductance of the conductive spark channel. Therefore, the equivalent electrical circuit of the discharge circuit takes the form (Fig. 6) [14].

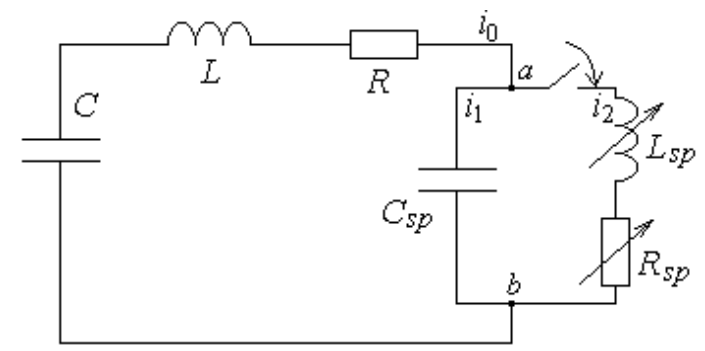

Fig. 6. Equivalent electrical circuit of the discharge circuit without a connected voltage probe [14]

Connecting the voltage divider to the discharge circuit leads to an increase in the total capacity of this circuit [12]. Also, such a connection affects the discharge processes by changing the equivalent circuit of the discharge circuit. Assuming that the resistance of the voltage probe is much greater than the resistance of the elements of the discharge circuit, this component can be neglected. As a result, the equivalent electrical circuit of the discharge circuit with the connected voltage probe is presented by a scheme (Fig. 7).

Moving the $c d$ nodes of the HV-probe along the connection wires causes a change in the inductances $L_{01}$ and $L_{02}$ and the resistance $R_{01}$ and $R_{02}$. It should be noted that even if the voltage divider is connected to the discharge capacitor or to the discharge electrodes, the 
presence of these inductances cannot be avoided. This is due to the fact that the capacitor has its self inductance and resistance and the discharge electrodes also include inductive elements with a certain resistance.

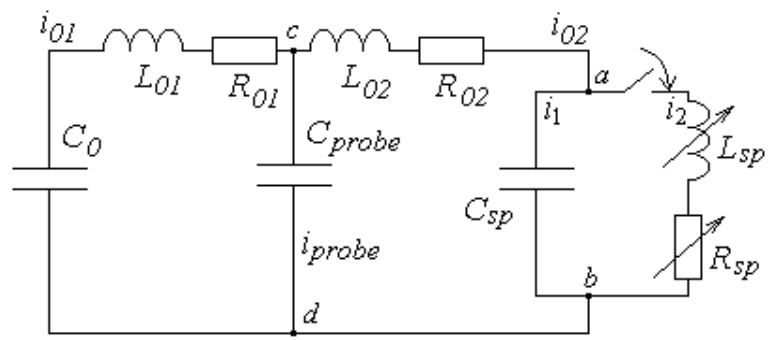

Fig. 7. Equivalent electrical circuit of the capacitor discharge with the connected voltage probe

These factors can be detected by modeling the transition process in the discharge circuit (see Fig. 6) by the following system of equations [14]:

$$
\begin{gathered}
\frac{1}{C} \int i_{0} d t+L \frac{d i_{0}}{d t}+R i_{0}+\frac{1}{C_{s p}} \int i_{1} d t=0 \\
-\frac{1}{C_{s p}} \int i_{1} d t+L_{s p} \frac{d i_{2}}{d t}+i_{2} \frac{d L_{s p}}{d t}+R_{s p} i_{2}=0 \\
i_{0}=i_{1}+i_{2} .
\end{gathered}
$$

Substituting into the system of equations the parameters of the investigated circuit $(C=4.9 \mu \mathrm{F} ; L=1.0 \mu \mathrm{H}$; $R=0.1 \Omega$ ), and assuming that the discharge gap with the voltage probe acquire the parameters $C_{s p}=30 \mathrm{pF}$; $L_{s p}=0.24 \mu \mathrm{H} ; R_{s p}=1 \Omega$, we obtain the following discharge current $i_{0}$ (Fig. 8).

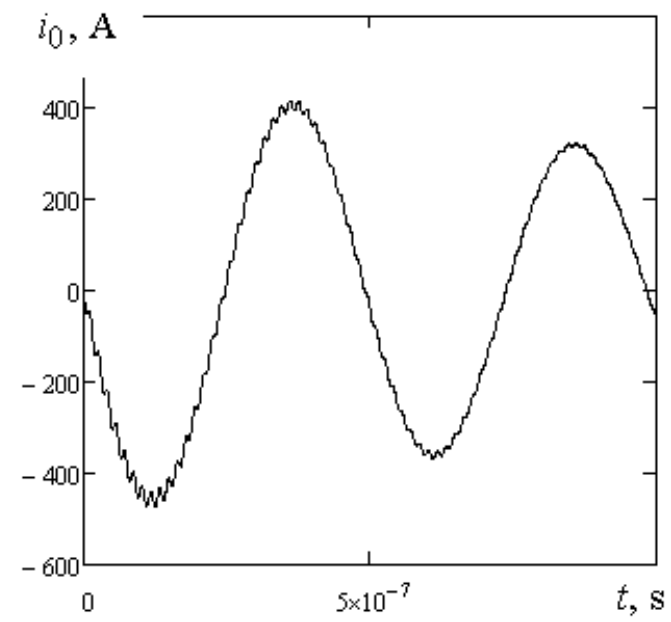

Fig. 8. Simulated current $i_{0}$

The obtained result qualitatively demonstrates the effect of connecting the voltage probe on the discharge current.

Taking into account that the connection of the voltage divider to the discharge gap leads to a change in the discharge current (see Figs. 3, 4), in this case, the results of measuring the voltage drop across the gap and discharge current are not correct to use for calculation the energy deposition in the discharge gap. Therefore, the investigation of the influence of the gap length and the initial gas pressure was carried out by numerical modeling of the spark discharge evolution using the measured discharge currents as the input data.

The result of the current and voltage measuring that occurs in the circuit with the gap length of $1 \mathrm{~mm}$, where the initial gas pressure was $0.2 \mathrm{MPa}$, is presented in Fig. 9. The voltage probe was connected to the capacitor. The result of the current and voltage measuring current with the length of $2 \mathrm{~mm}$ and the pressure of 0.1 $\mathrm{MPa}$ is presented in Fig. 10.

We observe from the obtained results that an initial voltage of the charged capacitor is the similar in both cases. And the largest current amplitude is reached on a discharge gap of the shortest length, despite the increase of the initial gas pressure in the gas-discharge medium.

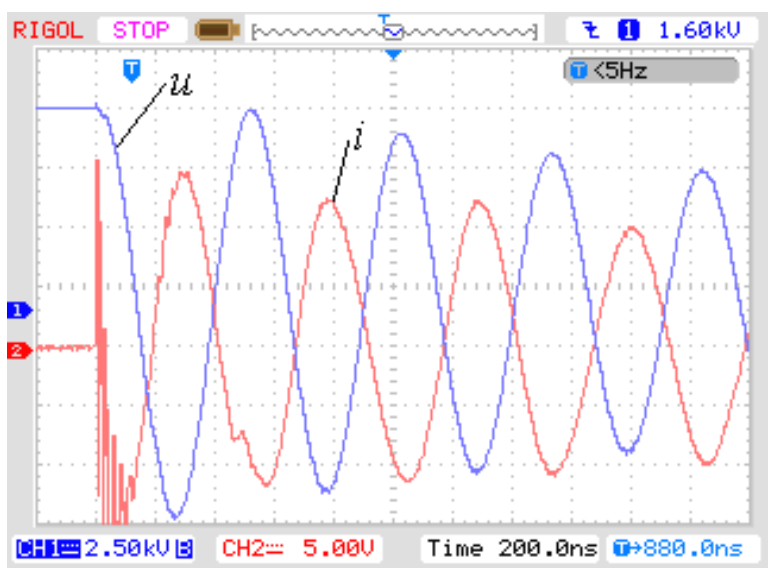

Fig. 9. Oscillograms of current $\boldsymbol{i}$ in the discharge circuit and voltage $\boldsymbol{u}$ by the length of $1 \mathrm{~mm}$ and an initial pressure of $0.2 \mathrm{MPa}$

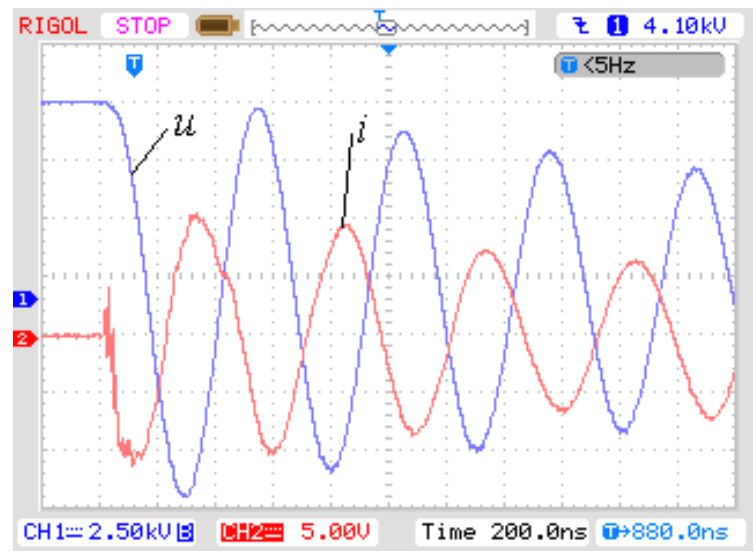

Fig. 10. Oscillograms of current $\boldsymbol{i}$ in the discharge circuit and voltage $\boldsymbol{u}$ by the length of $2 \mathrm{~mm}$ and an initial pressure of $0.1 \mathrm{MPa}$

To evaluate the energy of the spark discharge deposited into the discharge gap, the numerical model described in works [8-10] was used. The model is based on the equations of gas dynamics for compressible gas, the equations of nonequilibrium chemical kinetics, the equations of the gas state. The calculation of the electrical conductivity of gas in the temperature range over $10000 \mathrm{~K}$ is performed according to the Saha equations and the equation of conductivity of highly ionized gas. Heat transfer by radiation in a conductive channel is calculated by the equations of radiant thermal conductivity in a gray body.

The calculation results of the energy input into the 
spark channel and the resistance of the spark channel are presented in Figs. 11, 12.

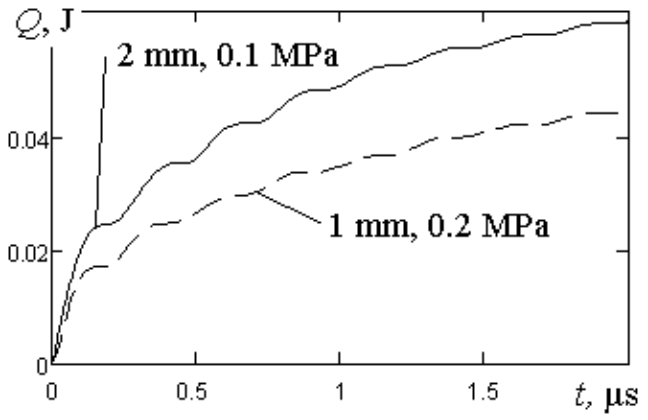

Fig. 11. The change in energy deposited into the spark channel over time

According to the results of numerical studies, we observe that an increase in the length of the gap under conditions of proportional pressure drop leads to an increase in the energy deposited into the spark channel (see Fig. 11). It should be noted that this increase occurs despite the decrease in the amplitude of the discharge current in the case of increasing the length of the gap (see Figs. 9, 10). The increase in energy under conditions of decreasing discharge current is caused by an increase in the resistance of the spark channel (see Fig. 12).

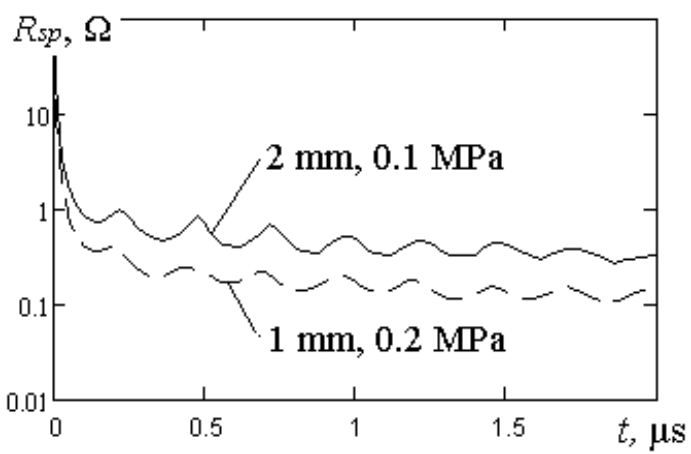

Fig. 12. Changing the resistance of the spark channel over time

The increase in the resistance of the spark gap explains the decrease in the amplitude of the discharge current obtained by the measurement results (see Figs. 9, 10).

In the conditions of the carried-out researches we have growth of the energy input into the spark channel in 1.35 times. It is known [1-5] that an increase in pressure and an increase in the length of the gap lead to an increase in the energy input. In particular, according to work [15], the energy input into the spark channel is directly proportional to the length of the gap. That is, a 2-fold increase in the length of the gap at constant discharge current leads to a 2-fold increase in the energy deposited into the discharge. According to work [8], a 2fold decrease in pressure leads to a decrease in energy deposited into the discharge by 1.2 times. Under these conditions, the energy would increase by 1.67 times. But it is necessary to take into account the increase in the resistance of the discharge channel happens in conditions of decreasing the amplitude of the discharge current in the investigated case. This explains the deviation of the obtained result from the result of other studies.
We have, according to obtained results, that the length of the discharge gap has a greater influence on the energy input when the same multiplicity of pressure change and the opposite change in the gap length take place.

\section{CONCLUSIONS}

Based on experimental and computational studies of the effect of the length of the discharge gap and the initial gas pressure on the energy input into the discharge channel, it was found that the gap length factor affects the energy input to the discharge channel more than the initial pressure factor. In particular, in the conditions of the conducted researches in case of increase of length of an interval in 2 times with simultaneous decrease in the pressure in 2 times there was an increase in the energy deposited into the spark channel in 1.35 times.

It is experimentally confirmed that the connection of the voltage probe to the discharge circuit, in conditions when the total discharge energy exceeds $100 \mathrm{~mJ}$, affects the discharge current. Therefore, for an adequate description of the discharge processes, it is advisable to consider the discharge circuit as a distributed-element circuit.

\section{REFERENCES}

1. C.J. Benito Parejo, Q. Michalski, C. Strozzi, J. Sotton, M. Bellenoue. Characterization of Spark Ignition energy transfer by optical and non-optical diagnostics // 8th European Combustion Meeting. 2017, p. 898-902.

2. L. Xiaoang, L. Xuandong, Fanhui Z, Hao Y, and Qiaogen Z. Study on Resistance and Energy Deposition of Spark Channel Under the Oscillatory Current Pulse // IEEE Transactions on Plasma Science. 2014, v. 42, p. 2259.

3. M. Belmouss. Effect of electrode geometry on high energy spark discharges in air // Thesis, Purdue University West Lafayette, Indiana, 2015.

4. V. Kamenskihs, H.D. Ng, J.H.S. Lee. Measurement of Critical Energy for Direct Initiation of Spherical Detonations in Stoichiometric High-Pressure $\mathrm{H}_{2}-\mathrm{O}_{2}$ Mixtures // Combustion and Flame. 2010, v. 157, p. 1795-1799.

5. J. Zhang, A.H. Markosyan, M. Seeger, E.M. van Veldhuizen, E.J.M. van Heesch, U. Ebert. Numerical and experimental investigation of dielectric recovery in supercritical $\mathrm{N}_{2}$ // Plasma Sources Sci. Technol. 2015, v. 24 , p. 025008.

6. Y. Tanaka, T. Michishita, Y. Uesugi. Hydrodynamic chemical non-equilibrium model of a pulsed arc discharge in dry air at atmospheric pressure // Plasma Sources Science and Technology. 2005, v.14, p. 134148.

7. Y Tanaka, T Sakuta. Modelling of a pulsed discharge in $\mathrm{N}_{2}$ gas at atmospheric pressure // Journal of Physics D: Applied Physics. 1999, v.32, p. 3199.

8. K. Korytchenko, S. Tomashevskiy, et al. Numerical investigation of energy deposition in spark discharge in adiabatically and isothermally compressed nitrogen // Japanese Journal of Applied Physics. 2020, v. 59, № SH. 
9. K. Korytchenko et al. Numerical simulation of initial pressure effect on energy input in spark discharge in nitrogen // Problems of Atomic Science and Technology. Series «Plasma Electronics and New Methods of Acceleration». 2019, N 122, p. 116-119.

10. K. Korytchenko et al. Numerical simulation of gap length influence on energy deposition in spark discharge // Electrical Engineering and Electromechanics. 2021, v. 1, p.43-51.

11. K. Korytchenko, S. Essmann, D. Markus, U. Maas, E. Poklonskii. Numerical and Experimental Investigation of the Channel Expansion of a Low-Energy Spark in the Air // Combustion Science and Technology. 2019, v. 191, p. 2136-2161.

12. B. Sforzo, J. Kim, A. Lambert, J. Jagoda, S. Menon, J. Seitzman. High energy spark kernel evolution: Meas- urements and modeling // 8th US National Combustion Meeting, University of Utah, May 19-22, 2013, p. 070IC-0272.

13. R. Payri, R. Novella, A. Garcia, V. Domenech. A new methodology to evaluate engine ignition systems in high density conditions // Experimental Techniques. 2014, v. 38, p.17-28.

14. K. Korytchenko, S. Essmann, R. Tomashevskiy, et al. Challenges of energy measurements of low-energy spark discharges // 2020 IEEE KhPI Week on Advanced Technology (KhPIWeek). 2020, p. 421-424.

15. I. Abramson, N. Gegechkory. Oscilloscope investigation of spark discherg // J. Exp. and Theor. Physics. 1951, v.21, p. 484-492.

Article received 16.11.2020

\title{
ЭКСПЕРИМЕНТАЛЬНОЕ И ЧИСЛЕННОЕ ИССЛЕДОВАНИЯ ВЛИЯНИЯ ДАВЛЕНИЯ И ДЛИНЫ РАЗРЯДНОГО ПРОМЕЖУТКА НА ВВОД ЭНЕРГИИ В ИСКРОВОМ РАЗРЯДЕ
}

\author{
К.В. Корытченко, И.С. Вариамова, Д.В. Мешков, Д.П. Дубинин, Р.И. Коваленко, \\ С.Ю. Назаренко
}

\begin{abstract}
Проведены исследования влияния длины разрядного промежутка и начального давления газа на введение энергии в разрядный канал. Исследования проведены при одинаковой полной энергии разряда. Экспериментально показано, что подключение делителя напряжения к разрядной цепи существенно влияет на разрядный ток. Определение энергии, вводимой в искровой канал, осуществлено по результатам численного моделирования развития искрового канала. В качестве исходных данных для расчета использованы экспериментально измеренные разрядные токи при различных давлениях и длинах разрядного промежутка. На основании полученных результатов определено, какой из факторов (начальное давление или длина промежутка) больше влияет на ввод энергии в искровой канал.
\end{abstract}

\section{ЕКСПЕРИМЕНТАЛЬНЕ I ЧИСЕЛЬНЕ ДОСЛІДЖЕННЯ ВПЛИВУ ТИСКУ ТА ДОВЖИНИ РОЗРЯДНОГО ПРОМІЖКУ НА ВВЕДЕННЯ ЕНЕРГІЇ В ІСКРОВИЙ РОЗРЯД}

\author{
К.В. Коритченко, І.С. Вариамова, Д.В. Меиков, Д.П. Дубінін, Р.І. Коваленко, \\ С.Ю. Назаренко
}

Проведено дослідження впливу довжини розрядного проміжку та початкового тиску газу на введення енергії в розрядний канал. Дослідження проведено за однакової повної енергії розряду. Експериментально показано, що підключення дільника напруги до розрядного ланцюга суттєво впливає на розрядний струм. Визначення енергії, що вводиться в іскровий канал, здійснено за результатами чисельного моделювання розвитку іскрового каналу. Як вихідні дані для розрахунку використано експериментально виміряні розрядні струми при різних тисках та довжинах розрядного проміжку. На підставі отриманих результатів визначено, який з чинників (початковий тиск або довжина проміжку) більше впливає на введення енергії в іскровий канал. 